\title{
ARTICLE
}

Received 23 May 2013 | Accepted 13 Sep 2013 | Published 1 Nov $2013 \quad$ DOl: 10.1038/ncomms3611

\section{Probing water micro-solvation in proteins by water catalysed proton-transfer tautomerism}

\author{
Jiun-Yi Shen ${ }^{1, \star}$, Wei-Chih Chao ${ }^{1, \star}$, Chun Liu1 ${ }^{1}$ Hsiao-An Pan ${ }^{1}$, Hsiao-Ching Yang ${ }^{2}$, Chi-Lin Chen ${ }^{1,2}$, Yi-Kang Lan², \\ Li-Ju Lin ${ }^{3}$, Jinn-Shyan Wang ${ }^{3}$, Jyh-Feng Lu ${ }^{3}$, Steven Chun-Wei Chou ${ }^{1}$, Kuo-Chun Tang ${ }^{1} \&$ Pi-Tai Chou ${ }^{1}$
}

Scientists have made tremendous efforts to gain understanding of the water molecules in proteins via indirect measurements such as molecular dynamic simulation and/or probing the polarity of the local environment. Here we present a tryptophan analogue that exhibits remarkable water catalysed proton-transfer properties. The resulting multiple emissions provide unique fingerprints that can be exploited for direct sensing of a site-specific water environment in a protein without disrupting its native structure. Replacing tryptophan with the newly developed tryptophan analogue we sense different water environments surrounding the five tryptophans in human thromboxane $A_{2}$ synthase. This development may lead to future research to probe how water molecules affect the folding, structures and activities of proteins.

\footnotetext{
${ }^{1}$ Department of Chemistry, Center for Emerging Material and Advanced Devices, National Taiwan University, Taipei 10617, Taiwan. ${ }^{2}$ Department of Chemistry, Fu-Jen Catholic University, New Taipei City 24205, Taiwan. ${ }^{3}$ School of Medicine, Fu-Jen Catholic University, New Taipei City 24205, Taiwan. * These authors contributed equally to this work. Correspondence and requests for materials should be addressed to H.-C.Y. (email: hcyang_chem@mail.fju.edu.tw) or to P.-T.C. (email: chop@ntu.edu.tw).
} 
$\mathrm{n}$ proteins, water ubiquitously participates in dictating structure and functionality, including protein secondary and tertiary structures, the spontaneous formation of membranes and the recognition of signaling molecules in signal transduction $^{1-3}$. Recent advances have provided more convincing evidence that the water molecules in proteins are key elements in activating bio-functionality such as enzymatic reactions ${ }^{4-7}$ or vice versa, the protein (for example, an antifreeze protein) may affect the organization of water molecules ${ }^{8}$. Probing the water environment of a specifically interesting site in proteins thus may pave a way to understanding the underlying mechanisms and functionality. Unfortunately, although enormous efforts have been made in the characterization of fundamental aqueous hydration phenomena on protein surfaces ${ }^{9-11}$, little insight has been gained into water micro-solvation in protein ${ }^{12,13}$. Most of the relevant approaches have focused instead on probing the polarity of the local environment in proteins, particular around the active sites, by means of fluorescence solvatochromism ${ }^{14,15}$.

To date, Trp in bacterial proteins has been popularly substituted by (7-aza)Trp or in part with (2-aza)Trp, in which the indole moiety in Trp is replaced by 7 -azaindole or 2-azaindole (Fig. 1), for either investigating the antimetabolic properties of the Trp isosteres ${ }^{16}$ or accessing the local polarity of Trp in proteins with unknown tertiary structures ${ }^{17-21}$. Catalysed by protic solvent molecules such as alcohols (for example, methanol), 7-azaindole undergoes solvent-assisted excited-state proton transfer (ESPT), resulting in an $\mathrm{N}_{7}-\mathrm{H}$ tautomer form (Fig. 2a) that exhibits green emission $(\sim 510 \mathrm{~nm})^{22-24}$. In water, however, the $\mathrm{N}_{7}-\mathrm{H}$ tautomer green emission is virtually nonobservable ${ }^{25}$; this lack has been attributed to the much slower proton-transfer rate constant $\left(\sim 10^{9} \mathrm{~s}^{-1}\right)$ together with dominant radiation-less deactivation pathways ${ }^{22}$. The photophysical properties of (7-aza)Trp are very similar to those of 7-azaindole, exhibiting essentially no $\mathrm{N}_{7}-\mathrm{H}$ tautomer form emission ${ }^{16,26-28}$ and thus cannot be used for probing any water-associated photophysical phenomena in proteins.

To surpass the limitation of the traditional Trp analogues, we strategically design a new type of aza-Trp by overlapping two azaindole parent moieties, that is, $\mathbf{2}$-azaindole and $\mathbf{7 - a z a i n d o l e , ~}$ yielding a new core moiety 2,7-diazaindole (Fig. 1) that is capable of sensing a protein water environment. The underlying concept originates from the molecule 3-cyano-7-azaindole ${ }^{29}$ (Fig. 1), in which the cyano electron-withdrawing ability increases hydrogen acidity of the $\mathrm{N}_{1}-\mathrm{H}$ form and hence facilitates the overall ESPT rate in water, rendering an intensive $\mathrm{N}_{7}-\mathrm{H}$ proton-transfer<smiles>NC(Cc1n[nH]c2ncccc12)C(=O)O</smiles>

(2,7-aza)Trp<smiles>c1cnc2[nH]ncc2c1</smiles>

2,7-diazaindole<smiles>Cn1ncc2cccnc21</smiles>

$\mathrm{N}(1)-\mathrm{Me}$<smiles>Cn1cc2cccnc2n1</smiles>

$\mathrm{N}(2)-\mathrm{Me}$ b<smiles>[131I]c1[nH][nH]c2cccc1-2</smiles>

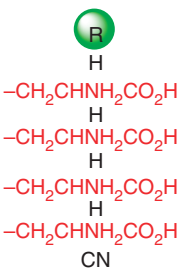

$\mathrm{CN}$

$\begin{array}{lll}\mathrm{R}_{2} & \mathrm{R}_{7} & \text { Compound } \\ \mathrm{C} & \mathrm{C} & \text { Indole } \\ \mathrm{C} & \mathrm{C} & \text { Trp } \\ \mathrm{C} & \mathrm{N} & \text { 7-azaindole } \\ \mathrm{C} & \mathrm{N} & \text { (7-aza)Trp } \\ \mathrm{N} & \mathrm{C} & \text { 2-azaindole } \\ \mathrm{N} & \mathrm{C} & (\text { (2-aza)Trp } \\ \mathrm{N} & \mathrm{N} & \mathbf{2 , 7 - d i a z a i n d o l e} \\ \mathrm{N} & \mathrm{N} & (\text { 2,7-aza)Trp } \\ \mathrm{C} & \mathrm{N} & \text { 3-cyano-7-azaindole }\end{array}$

Figure 1 | The structural formulae of relevant indole and tryptophan derivatives. (a) The chemical structures of (2,7-aza)Trp, 2,7-diazaindole, $\mathbf{N}(\mathbf{1})-\mathbf{M e}$ and $\mathbf{N}(\mathbf{2})-\mathbf{M e}$. (b) The chemical structures of various indole and tryptophan analogues. tautomer emission in the green (Fig. 2a). For 2,7-diazaindole, the replacement of pyrrole by the pyrazole moiety, in which the $\mathrm{N}(2)$ atom acts as an efficient electron-withdrawing group ${ }^{30}$, is expected to increase the $\mathrm{N}_{1}-\mathrm{H}$ proton acidity without perturbing the parent geometry. Using 2,7-diazaindole as the core moiety, we further develop a new Trp analogue, (2,7-aza)Trp (Fig. 1), that exhibits remarkably different properties from classical azaTrp analogues in that water-assisted proton-transfer isomerization takes place in both the excited and the ground states (Fig. 2a,b). The proposed schematic diagram of the protontransfer cycle for 2,7-diazaindole and (2,7-aza)Trp is depicted in Fig. 2c. Figure 2c unveils the water-catalysed isomerization between the $\mathrm{N}_{1}-\mathrm{H}$ form and the $\mathrm{N}_{2}-\mathrm{H}$ form in the ground state and ESPT for the $\mathrm{N}_{1}-\mathrm{H}$ form in the excited state, as supported by the following firm spectroscopy and dynamics evidence. The associated multiple emissions thus serve as a unique fingerprint

a<smiles></smiles>

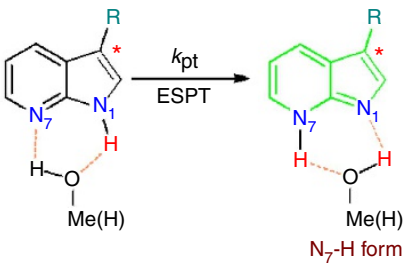

b

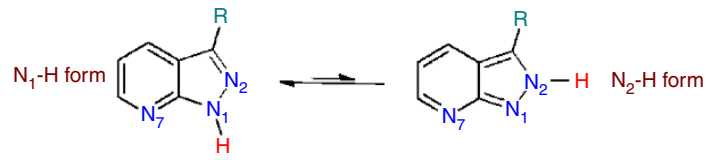

c

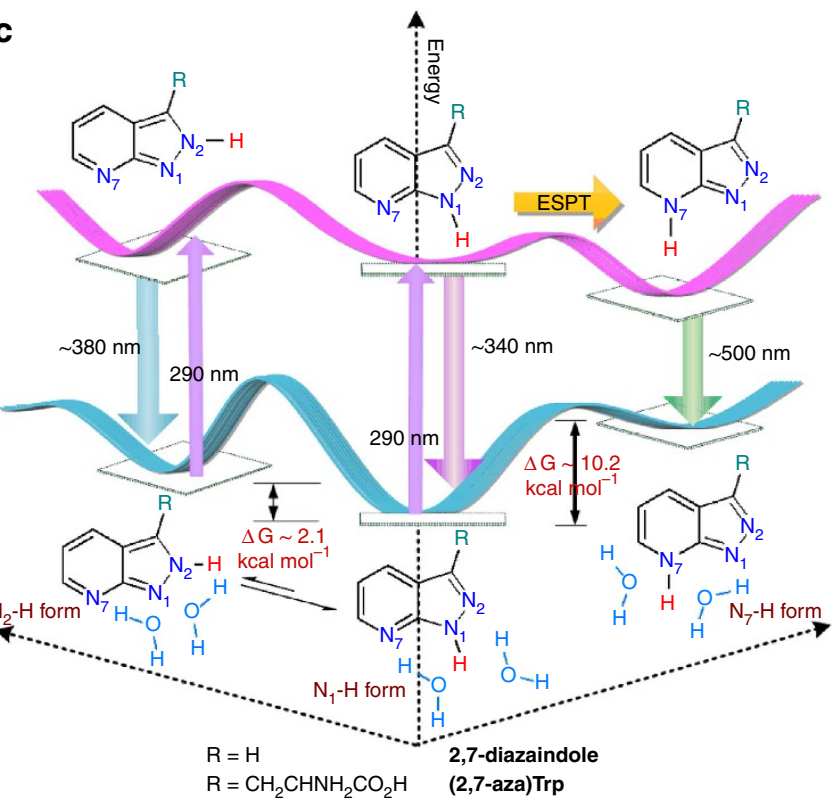

Figure 2 | Proposed ground and electronically excited states mechanism. (a) The proposed protic solvent catalysed ESPT mechanism for 7-azaindole and its derivatives. The asterisk * indicates the electronically excited state. This mechanism incorporates a fast excited-state equilibrium between polysolvated and 1:1 cyclic hydrogen-bonded $\mathrm{N}_{1}-\mathrm{H} / \mathrm{H}_{2} \mathrm{O}$ (or methanol) followed by proton tunnelling $k_{\mathrm{pt}}^{22}$, which has been unambiguously proved by the kinetic deuterium isotope effect ${ }^{29}$. Under the assumption of $k_{-1}>k_{1}$ and $k_{\mathrm{pt}}$, the overall ESPT rate constant $k_{\mathrm{rxn}}$ can be expressed as $k_{\mathrm{rxn}}$ $=\left(k_{1} / k_{-1}\right) k_{\text {pt }}$. (b) The ground-state equilibrium for 2,7-diazaindole and its derivatives between $\mathrm{N}_{1}-\mathrm{H}$ form and $\mathrm{N}_{2}-\mathrm{H}$ form isomers in water. (c) The proposed schematic diagram of a proton-transfer cycle for $\mathbf{2 , 7 - d i a z a i n d o l e ~}$ and (2,7-aza)Trp in water, in which the barrier and hence potential energy surface are arbitrarily chosen. 
for sensing the water environment. The proof of concept is made by the site-specific substitution (2,7-aza)Trp for tryptophan in human thromboxane $\mathrm{A}_{2}$ synthase (TXAS) to resolve a distinct water environment in various Trp sites of TXAS.

\section{Results}

Proton-transfer tautomerism. Manifested in neutral water $(\mathrm{pH}=7.0)$, either (2,7-aza)Trp or 2,7-diazaindole reveals remarkable triply fluorescent bands (Fig. 3a,b and Table 1), consisting of an apparent shoulder at $\sim 330 \mathrm{~nm}$, a peak wavelength at $\sim 370 \mathrm{~nm}$ and a much red-shifted emission band maximized at $\sim 500 \mathrm{~nm}$, corresponding to the existence of $\mathrm{N}_{1}-\mathrm{H}$, $\mathrm{N}_{2}-\mathrm{H}$ and $\mathrm{N}_{7}-\mathrm{H}$ isomers, respectively, in the excited state. The excitation spectra at $335 \mathrm{~nm}$ and at the very red edge (for example, $530 \mathrm{~nm}$ ) of the emission are identical and they also resemble the absorption spectrum (Supplementary Fig. S1). As 2,7-diazaindole and (2,7-aza)Trp were synthesized independently from different methods (Supplementary Fig. S2 and Supplementary Methods), the possibility of trace impurities contributing to the triple emission bands can be eliminated. Rather, the triple emission can be well rationalized by the protontransfer tautomerism in both ground and excited states. Support is provided chemically by the methyl derivatives of 2,7-diazaindole, $\mathrm{N}(1)-\mathrm{Me}$ and $\mathrm{N}(2)-\mathrm{Me}$ (Fig. 1), which exhibit prominent emissions at 342 and $367 \mathrm{~nm}$, respectively, in neutral water (Fig. 3c and Supplementary Fig. S3). The emission of N(2)-Me, in view of the peak position $(367 \mathrm{~nm})$, is nearly identical to that $(370 \mathrm{~nm})$ of 2,7 -diazaindole, so the assignment of 2,7-diazaindole $370 \mathrm{~nm}$ emission to the $\mathrm{N}_{2}-\mathrm{H}$ isomer appears unambiguous. In addition, given the similarity of its emission peak wavelength $(342 \mathrm{~nm})$ to that of $\mathbf{N}(\mathbf{1})-\mathbf{M e}$, the $335 \mathrm{~nm}$ band in 2,7-diazaindole can reasonably be ascribed to the emission of the $\mathrm{N}_{1}-\mathrm{H}$ isomer. The difference in excitation origins for 335 and $370 \mathrm{~nm}$ emission bands (Supplementary Fig. S1) clearly indicates the existence of ground-state equilibrium between $\mathrm{N}_{1}-\mathrm{H}$ and $\mathrm{N}_{2}$ $\mathrm{H}$ isomers for 2,7-diazaindole (Fig. 2b). In accordance with this assignment, we also propose the occurrence of water-catalysed ESPT in the $\mathrm{N}_{1}-\mathrm{H}$ form, forming the $\mathrm{N}_{7}-\mathrm{H}$ isomer, to account for the $\sim 500 \mathrm{~nm}$ green emission. Taking account of the structural and spectral similarity, the same assignment of the triple emission should hold true for (2,7-aza)Trp.

Firm support for the tautomerism is given by the correlation of relaxation dynamics among emission bands (Table 1). At the short wavelength shoulder of $320 \mathrm{~nm},(2,7$-aza)Trp exhibits a single decay component of $260 \mathrm{ps}$ in water. At the red edge of the green emission $(540 \mathrm{~nm})$, the relaxation dynamics consist of a finite rise component ( $263 \mathrm{ps)}$ ) and a decay component with a lifetime of $0.58 \mathrm{~ns}$ (Fig. $3 \mathrm{~d}$ and Table 1). The 263 ps rise dynamic, within experimental uncertainty of $\pm 30 \mathrm{ps}$, correlates well with the decay of the $340 \mathrm{~nm}$ band, supporting the precursor $(340 \mathrm{~nm}$ band) and successor (500 $\mathrm{nm}$ band) type of reaction kinetics and hence the water-assisted ESPT for the $\mathrm{N}_{1}-\mathrm{H}$ isomer. On the other hand, the relaxation dynamics at the peak wavelength of $380 \mathrm{~nm}$ consists of an instant, system-response-limited rise time ( $<60 \mathrm{ps}$ ), accompanied by two decay components, one with a small amplitude $(\sim 12 \%)$, fast decay $(265 \mathrm{ps})$, and a major, long decay component $(88 \%, 10.07$ ns, see Fig. 3e). The former 265 ps
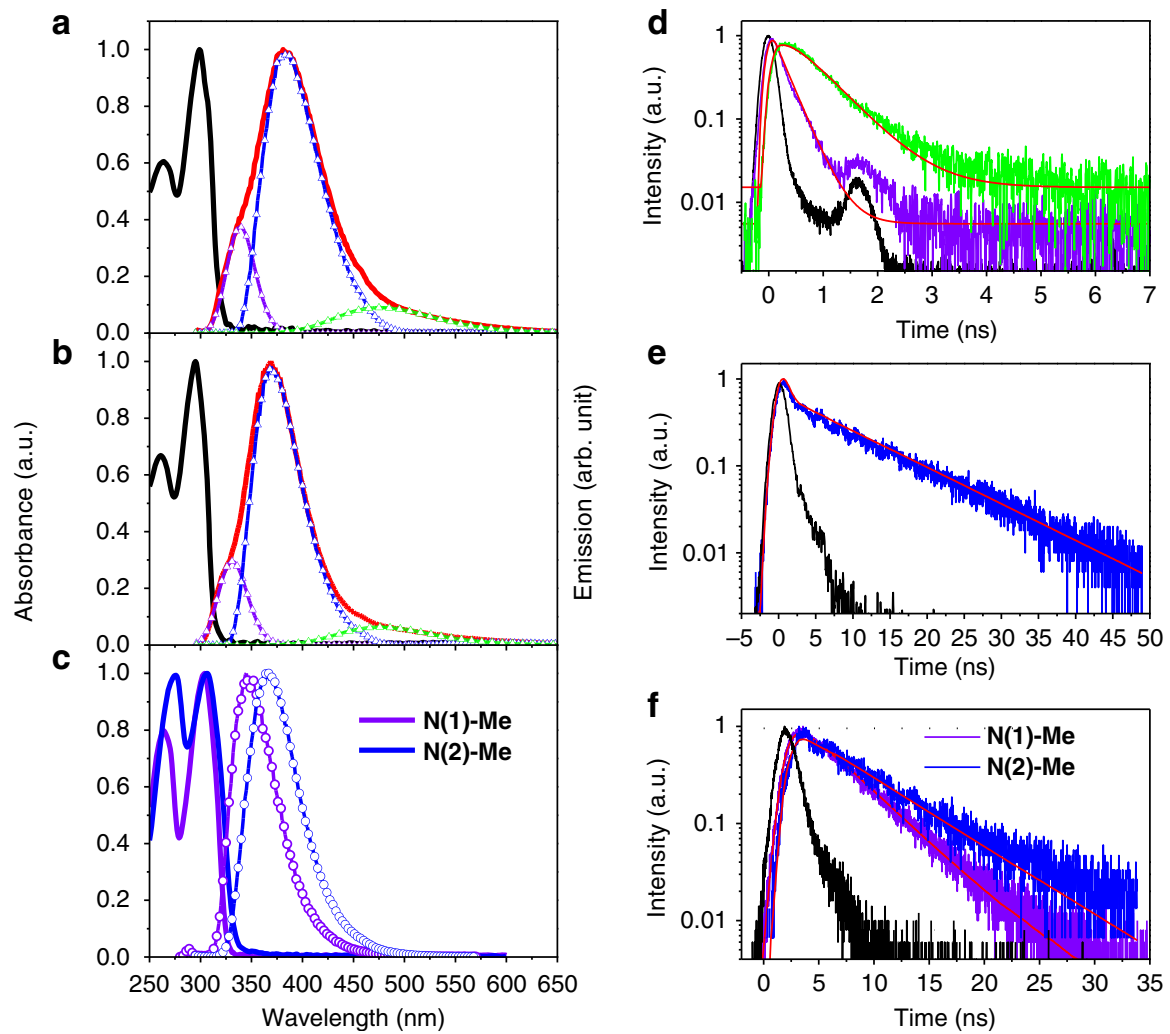

Figure 3 | Identification of the triple emission bands. (a,b) Absorption (black) and emission spectra (red) of (2,7-aza)Trp are shown in a and 2,7-diazaindole are shown in (b) in neutral water. Further, the decomposed PL spectra are shown (violet, blue and green triangles). $\lambda_{\mathrm{ex}}=290 \mathrm{~nm}$. (c) Absorption and emission spectra of $\mathbf{N}(\mathbf{1})-\mathbf{M e}$ and $\mathbf{N ( 2 )}$-Me in neutral water. (d) The emission decay dynamics of (2,7-aza)Trp monitored at $320 \mathrm{~nm}$ (violet) and $540 \mathrm{~nm}$ (green). (e) The emission decay dynamics of (2,7-aza)Trp monitored at $380 \mathrm{~nm}$. (f) The emission decay dynamics of $\mathbf{N}(\mathbf{1})$-Me and N(2)-Me. The instrument response and the fitting curves are marked in black and red lines, respectively. The residuals of the fit of emission decay dynamics as shown in Supplementary Fig. S8. 
Table 1 | Photophysical properties.

\begin{tabular}{|c|c|c|c|c|}
\hline & $\lambda_{\mathrm{abs}}(\mathrm{nm})$ & $\lambda_{\mathrm{em}}(\mathrm{nm})$ & $\lambda_{\text {mon }}(\mathrm{nm})^{\dagger}$ & $\tau(\mathbf{n s})^{\ddagger}$ \\
\hline (7-aza)indole ${ }^{\S}$ & 288 & 386 & & 0.91 \\
\hline (7-aza)Trp & 289 & 400 & & 0.65 \\
\hline \multirow[t]{2}{*}{ 2,7-diazaindole } & 295 & 335 & 320 & 0.22 \\
\hline & & 495 & 550 & 0.21 (rise), 1.30 \\
\hline \multirow[t]{2}{*}{$(2,7-a z a) T r p$} & 300 & 340 & 320 & 0.26 \\
\hline & & 380 & 380 & $0.27(12 \%), 10.07(88 \%$ \\
\hline$N(2)-M e$ & 306 & 367 & 370 & 5.20 \\
\hline \multirow[t]{2}{*}{$(2,7$-aza)Trp $31,65,133,203,446$-TXAS } & 300 & 338 & 350 & $0.31(83 \%), 1.60(17 \%)$ \\
\hline & & 507 & 520 & 0.27 (rise), 1.18 \\
\hline \multirow[t]{2}{*}{$(2,7-a z a) \operatorname{Trp}{ }^{31,133,203,446} \mathrm{Phe}^{65}$-TXAS } & 300 & 340 & 350 & 0.28 \\
\hline & & 503 & 520 & 0.31 (rise), 1.12 \\
\hline \multirow[t]{2}{*}{$(2,7-a z a) \operatorname{Trp}{ }^{31} \mathrm{Phe}^{65,133,203,446}$-TXAS } & 300 & 341 & 350 & 0.29 \\
\hline & & 507 & 520 & 0.30 (rise), 1.23 \\
\hline \multirow[t]{2}{*}{$(2,7-a z a) \operatorname{Trp}{ }^{446} \mathrm{Phe}^{31,65,133,203}$-TXAS } & 300 & 341 & 350 & 0.30 \\
\hline & & 503 & 520 & 0.30 (rise), 1.41 \\
\hline
\end{tabular}

component in the $380 \mathrm{~nm}$ emission decay, within the experimental error, is identical to $260 \mathrm{ps}$ monitored at $320 \mathrm{~nm}$ and thus is assigned to the residue of the $\mathrm{N}_{1}-\mathrm{H}$ emission band. The latter is the population decay of the $\mathrm{N}_{2}-\mathrm{H}$ form emission. The same correlation among the triple emission bands is also resolved for 2,7-diazaindole (Table 1), supporting firmly that both 2,7diazaindole and (2,7-aza)Trp in water undergo proton-transfer tautomerism in the ground state $\left(\mathrm{N}_{1}-\mathrm{H} / \mathrm{N}_{2}-\mathrm{H}\right.$ equilibrium) and the excited state $\left(\mathrm{N}_{1}-\mathrm{H} \rightarrow \mathrm{N}_{7}-\mathrm{H}\right.$ proton transfer).

One fundamental issue lies in the thermodynamics between $\mathrm{N}_{1}-\mathrm{H}$ and $\mathrm{N}_{2}-\mathrm{H}$ isomers in water (Fig. 2b). Experimentally, the molar absorption coefficient of $\mathrm{N}(2)-\mathrm{Me}, 5.3 \times 10^{3} \mathrm{M}^{-1} \mathrm{~cm}^{-1}$ (at $320 \mathrm{~nm}$ ), was adopted for the $\mathrm{N}_{2}-\mathrm{H}$ isomer of 2,7-diazaindole at $320 \mathrm{~nm}$, a wavelength that is free from $\mathrm{N}_{1}-\mathrm{H}$ form interference. A known concentration of 2,7-diazaindole was prepared, and the $\mathrm{N}_{2}-\mathrm{H} / \mathrm{N}_{1}-\mathrm{H}$ equilibrium constant was measured to be 0.024 (detail in Supplementary Methods), corresponding to a difference of free energy of $2.2 \mathrm{kcal} \mathrm{mol}^{-1}$ at $298 \mathrm{~K}$. This value is in good agreement with the computational calculations, estimating that the $\mathrm{N}_{2}-\mathrm{H}$ form is $2.1 \mathrm{kcal} \mathrm{mol}^{-1}$ higher in energy than the $\mathrm{N}_{1}-\mathrm{H}$ form for 2,7-diazaindole in water. The same trend is observed but with a rising difference if we consider that less polar solvation by benzene, $\mathrm{N}_{2}-\mathrm{H}$ form, has a higher energy by $6.3 \mathrm{kcal} \mathrm{mol}^{-1}$ for 2,7-diazaindole. We find that this is true with no detectable $\mathrm{N}_{2}-\mathrm{H}$ isomer form emission resolved in organic solvents for 2,7diazaindole (Supplementary Figs S4 and S5). This proton transfer induced multiple emission in water is remarkable and proves to provide fingerprints for probing a protein water environment.

TXAS homology structure and substrate/water gating channel. The focus of probing water in proteins is on the cytochrome P450 superfamily because recent advances have generated more convincing data indicating that water molecules have pivotal roles in the organism metabolic pathways in $\mathrm{P} 450 \mathrm{~s}^{31-33}$. We herein selected the structurally pending TXAS ${ }^{34-36}$, an endoplasmic reticulum membrane protein containing five tryptophans, as a prototype to demonstrate the feasibility of $(2,7-\mathbf{a z a}) \operatorname{Trp}$ in probing water environments. The atypical catalysis without reductase or oxygen and the pathogenesis of major diseases make TXAS of prime interest to elucidate the corresponding structure-function relationship ${ }^{37}$. One recent advance indicates that W65 of TXAS is likely to be in a hydrophobic pocket surrounded by the Phe-cluster, whereas the environment of the other four tryptophans is yet to be determined ${ }^{38}$. A prior molecular dynamic (MD) simulation in this study unveils the spatial arrangement of these five tryptophan residues relative to the haem group and gating channels of TXAS (Fig. 4a,b), where W65 residue is on the substrate channel, W133 is located on the aqueduct water channel, W31 lies in the $\mathrm{NH}_{2}$-terminal loop and W203 and W446 are close to the protein surface (detail in Supplementary Fig. S6).

Expression and analytics of (2,7-aza)Trp-TXAS. To examine the relevant tryptophans positions, TXAS mutants were synthesized in Trp-auxotrophic Escherichia coli cells ${ }^{39}$, and they proved to be capable of co-translational incorporation by site-specifically replacing Trp residues with (2,7-aza)Trp (see Supplementary Methods). Fig. 4d and e depict the fluorescence spectra of various mutants. As for single (2,7-aza)Trp substitution at W31, W133, W203 and W446, the resulting (2,7-aza)Trp ${ }^{31} \mathbf{P h e}^{\mathbf{6 5}, 133,203,446}$ -TXAS, (2,7-aza)Trp ${ }^{133}$ Phe $^{31,65,203,446}$-TXAS, (2,7-aza)Trp ${ }^{203}$ Phe ${ }^{31,65,133,446}$-TXAS and (2,7-aza)Trp ${ }^{446}$ Phe $^{31,65,133,203}$-TXAS exhibit prominent, well-resolved dual emissions maximized at $\sim 340 \mathrm{~nm}\left(\mathrm{~N}_{1}-\mathrm{H}\right)$ and $\sim 505 \mathrm{~nm}\left(\mathrm{~N}_{7}-\mathrm{H}\right)$, indicating the occurrence of $\mathrm{N}_{1}-\mathrm{H}$ to $\mathrm{N}_{7}-\mathrm{H}$ proton-transfer in the excited state. By taking advantage of the MD simulations, we were able to examine the proximal environment around various Trp sites of TXAS. We found no relevant amino acids forming direct $\mathrm{H}$-bonds with the mutant (2,7-aza)Trps, also eliminated the possibility of the ESPT catalysed from the protic residues. Therefore, the results ensure the water-catalysed ESPT for the single (2,7-aza)Trp substitution at each of four Trp sites in TXAS. For (2,7-aza)Trp substitution 

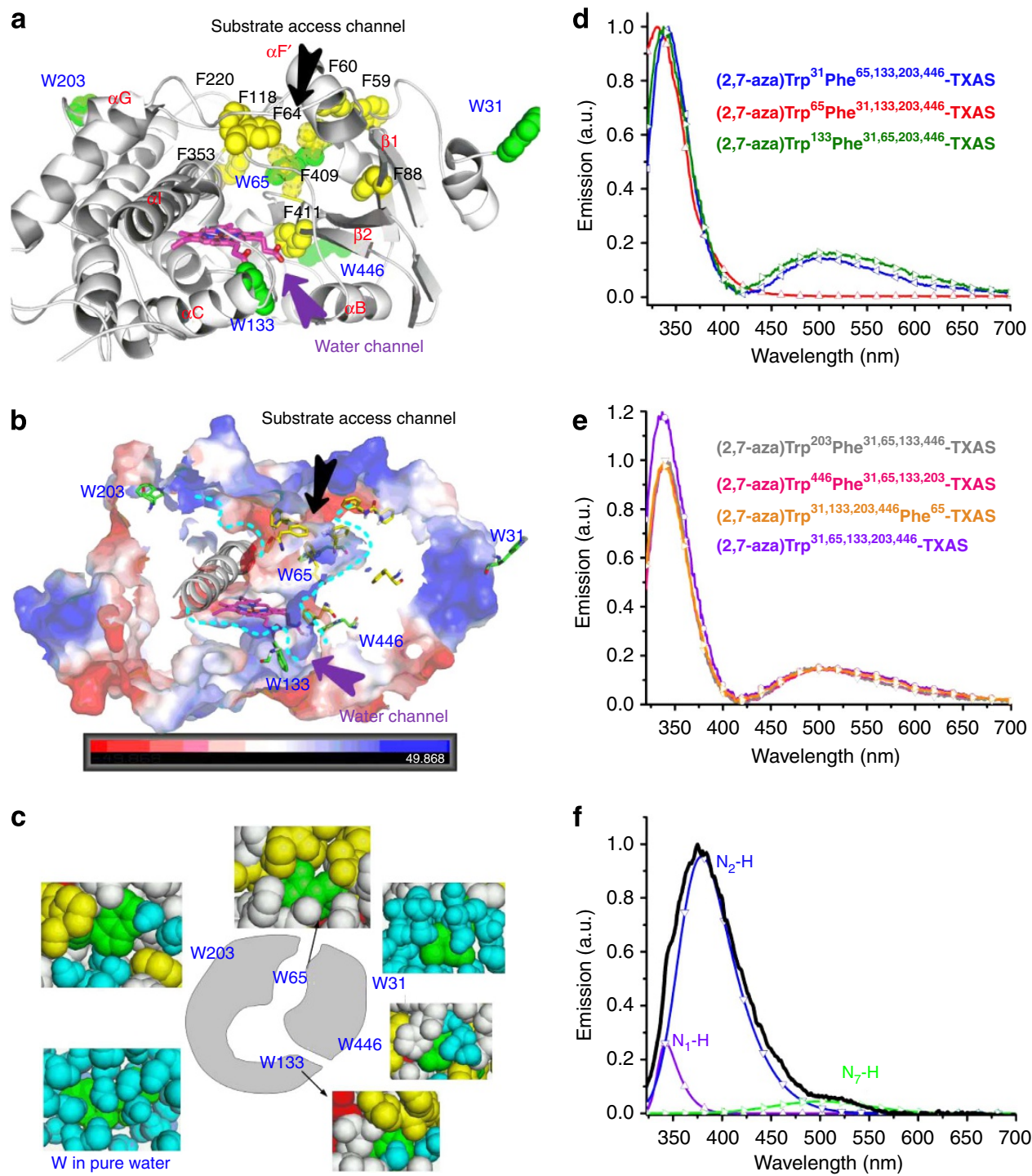

Figure 4 | MD simulation of TXAS protein and expression of TXAS mutants. (a) TXAS homology structure shows the characteristic P450 fold, illustrating the phenylalanine residues (yellow), five tryptophan positions (green) and haem (stick figures in violet). (b) The solvent-accessible surfaces of the active site cavities calculated using an $\mathrm{H}$ probe under an electrostatic potential (ESP) surface with electrophile/nucleophile (blue/red). Proposed gating channels are indicated. (c) The local environment of tryptophan (W) in hydrated TXAS (or water), in which W is shown in green, water is blue, acidic residues are red, hydrophobic residues are yellow and other residues are white. (d,e) Emission spectra of various TXAS mutants excited at 310 nm.

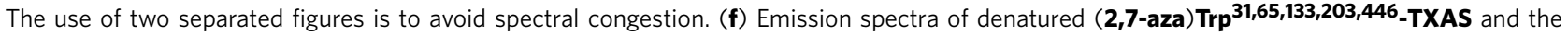
decomposed PL spectra.

at W31, W203 and W446, time-resolved measurement monitored at $350 \mathrm{~nm}$ clearly reveals a major $0.28-0.30 \mathrm{~ns}( \pm 0.03)$ decay component, which correlates well with the rise time of the $\sim 505 \mathrm{~nm}$ emission band of 0.30-0.32 ns ( \pm 0.03 ) (Table 1). Both spectroscopy and dynamics data are reminiscent of the water-catalysed ESPT of the (2,7-aza)Trp $\mathrm{N}_{1}-\mathrm{H}$ isomer in water. As shown in Fig. 4d, the observed dual emission also guarantees the occurrence of water-catalysed ESPT for single (2,7-aza)Trp-substituted TXAS mutants at W133. However, compared with that of W31, the slight increase of green tautomer emission intensity and the associated faster rate of ESPT $(0.21 \pm 0.03 \mathrm{~ns}$, Table 1$)$ may imply its difference in a water environment. Supported by water titration experiments for 7 -azaindole ${ }^{25,40}$, the breakdown of bulk water clusters may facilitate the rate of ESPT. Accordingly, we tentatively propose that there is a reduced water density region at the W133 site (cf. W31). The results of MD simulation elaborated in a later section seem to support this viewpoint.

In sharp contrast, for the single (2,7-aza)Trp substitution at W65, the resulting (2,7-aza)Trp ${ }^{65} \mathbf{P h e}^{\mathbf{3 1}, \mathbf{1 3 3}, 203,446}$-TXAS exhibits solely an emission band maximized at $332 \mathrm{~nm}$ with a long lifetime of $\sim 1.55 \mathrm{~ns}$ (Fig. $4 \mathrm{~d}$ and Table 1 ). The apparent lack of a $500 \mathrm{~nm}$ emission band speaks to the nature of the prohibition of ESPT at the W65 position in TXAS, concluding the deficiency of water molecules surrounding the proximity of the W65 site. Support is further given by the full (2,7-aza)Trp substitution of all five tryptophan residues in the expression of (2,7aza)Trp $31,65,133,203,446$-TXAS mutant, which exhibits wellresolved dual emissions maximized at $\sim 340$ and $507 \mathrm{~nm}$ as well (Fig. 4e). Notice that the intensity ratio for the $340 \mathrm{~nm}$ emission band versus the $500 \mathrm{~nm}$ emission band is slightly higher 
than that of quadruple (2,7-aza)Trp substitution of (2,7aza)Trp ${ }^{31,133,203,446}$ Phe $^{65}$-TXAS mutant, indicating the increase of $340 \mathrm{~nm}$ emission due to the prohibition of ESPT in $(2,7-$ aza)Trp65. Statistically, however, the mixture of incomplete substitution of (2,7-aza)Trp at any Trp sites is likely to occur in $(2,7-a z a) T r p^{31,65,133,203,446}$-TXAS. Therefore, the corresponding quantitative spectral analysis is not possible. Nevertheless, the selected excitation wavelength at $310 \mathrm{~nm}$ should be virtually free of absorption by trace Trp residues. Unambiguously, the results present a unique feature, that the position at W65 is subject to a water-deficient microenvironment wherein the lack of surrounding water molecules prohibits ESPT, resulting in a solely normal $\mathrm{N}_{1}-\mathrm{H}$ form $340 \mathrm{~nm}$ emission. The other four tryptophans (W31, W133, W203 and W446) in TXAS are in a water-accessible microenvironment that catalyses ESPT, resulting in an $\mathrm{N}_{7}-\mathrm{H}$ tautomer green emission.

Importantly, unlike the triple emission of dissolved (2,7aza)Trp in water, all native (2,7-aza)Trp-TXAS mutants reveal an absence of $\mathrm{N}_{2}-\mathrm{H}$ form $380 \mathrm{~nm}$ emission ( $c f$. Figs $3 \mathrm{a}$ and $4 \mathrm{~d}, \mathrm{e}$ ). This seems to describe the vital folding structure of a solvated protein. In a native folding, the associated framework in protein (TXAS) is different from the unfolding residues exposed in the bulk water solution, in which the $\mathrm{N}_{2}-\mathrm{H}$ isomer is solvated and stabilized at the sufficient water hydration level. Moreover, the TXAS conformer polarity may not be high enough to stabilize the $\mathrm{N}_{2}-\mathrm{H}$ isomer, being similar to the lack of population of $\mathrm{N}_{2}-\mathrm{H}$ isomer in organic solvents (vide supra, see Supplementary Fig. S4, in methanol). Firm support of this viewpoint is given by the reappearance of the $\mathrm{N}_{2}-\mathrm{H}$ form $380 \mathrm{~nm}$ emission upon denaturing of (2,7-aza)Trp ${ }^{31,65,133,203,446}$-TXAS variants (Fig. 4f). The lack of $\mathrm{N}_{2}-\mathrm{H}$ isomer emission thus indicates that none of the $(2,7-$ aza)Trp in (2,7-aza)Trp-TXAS mutants are bulk water-solvated, and so the Trps in wild-type TXAS, due to the structural similarity.

Explicit solvent MD simulations on both wild-type TXAS and (2,7-aza)Trp-replaced TXAS have been performed and showed no detectable differences in terms of the solvated homology structure. The results indicate that the TXAS matrices are dynamically coupled to the hydration water by a relay-type of hydrogen-bonding configuration (Fig. 4c). This, together with the close-up inspections of the hydrogen-bonding configurations for each (2,7-aza)Trp-replaced tryptophans in TXAS (Supplementary Fig. S6), draws two important remarks. First, there are clearly no water molecules surrounding the W65 site. Second, except for W65, water micro-solvation does exist for all other (2,7-aza)Trp. When compared with explicit water MD simulations, a locally fluctuating density profile is revealed (detail in Supplementary Methods and Supplementary Fig. S7), so it seems to be apparent that fewer trapped water molecules associate with the W133 site. Both results are consistent with the experimental observation (vide supra). The combination of experimental and MD approaches thus proves the feasibility of (2,7-aza)Trp in probing the micro-solvation structures in protein.

As manifested by explicit solvent MD simulations, two distinct channels are identified as the substrate access channel (W65 locus) and the aqueduct water channel (W133 locus) in protein TXAS (Fig. 4b). The associated faster rate of ESPT in (2,7aza)Trp133 seems to specify the destination of hydration water behaviours between the protein surface and aqueduct water channel in protein. Also worthy of note is the hydrophobic region located on the substrate channel; this region, with phenylalanine residues (Phe60, Phe64, Phe127, Phe220, Phe409 and Phe411) and W65, forms a 'Phe-cluster'. This distinctive Phe-cluster and hydrophobic residues on the TXAS substrate channel ${ }^{38}$ result in a less polar and water-deficient microenvironment at the active site, which is in stark contrast to its counter-enzyme prostacyclin synthase (PGIS), which has greater water accessibility to the active haem site $e^{39,41}$. This prediction is firmly supported by the prohibition of ESPT in (2,7-aza)Trp65. The location of the Phecluster results in a gating conformation of the active site of TXAS. $\mathrm{MD}$ simulations also reveal that conformational movement of the Phe-cluster residues could open/close the channel and consequently increase/decrease the volume of the active site of TXAS. We hypothesize that this relevant locus of the 'Phe-cluster' is crucial in gating different ligand/water access in an early step of allowance to the active haem site.

\section{Discussion}

In summary, we have developed a new tryptophan analogue, (2,7aza)Trp, which undergoes water-catalysed proton-transfer tautomerism in both ground and excited states, giving a multiple emission that is sensitive to the water environment. Incorporating (2,7-aza)Trp into human TXAS, we then demonstrate for the first time the feasibility to probe water molecules surrounding in proteins. Manifested by explicit solvent MD simulation, (2,7aza)Trp-TXAS mutant maintains its parent wild-type TXAS structure. Exploiting co-translational (2,7-aza)Trp as a probe, correlation between these biocompatible probing spectra and a water micro-solvation environment has been established, thereby identifying specific tryptophan locations on TXAS. The incorporation of (2,7-aza)Trp into TXAS proves $(2,7-\mathbf{a z a}) \operatorname{Trp}$ to be a novel optical probe that allows transmission of its surrounding water environment into unique fluorescence spectral features. In combination with in-depth MD simulation, future quantitative correlation for the ESPT dynamics versus number/orientation of water molecules is feasible, showing different hydration environments between the substrate access channel, aqueduct water channel and protein surface in, for example, TXAS. The superb water-sensing capability in terms of ESPT and ground-state $\mathrm{N}_{1}$ $\mathrm{H} / \mathrm{N}_{2}-\mathrm{H}$ equilibrium thus provides an unprecedented tool for probing the water environment in bio-systems on a structural basis.

\section{Methods}

General synthesis and characterization. Full experimental details, synthesis and characterization for all compounds, computational methodology, growth and induction of bacteria are included in the Supplementary Methods.

Steady-state and time-resolved fluorescence spectroscopy. Steady-state absorption and emission spectra were recorded on a Hitachi (U-3310) spectrophotometer and an Edinburgh (FS920) fluorimeter, respectively. Both wavelengthdependent excitation and emission response of the fluorimeter had been calibrated. Time-resolved spectroscopic measurements were carried out by means previously reported elsewhere in detail ${ }^{42,43}$. Briefly, nanosecond (ns) lifetime studies were performed with a time-correlated single-photon counting (TCSPC, Edinburgh FL 900), using a hydrogen-filled lamp as the excitation source. The emission decays were analysed by the sum of exponential functions as below, which allows partial elimination of instrument time broadening and thus renders a temporal resolution of $\sim 300$ ps. To achieve a faster time resolution, studies were also performed using a TCSPC system (Edinburgh OB-900L) coupled with an excitation light from the third harmonic generation (THG, at $306 \mathrm{~nm}$ ) of pulse-selected femtosecond laser pulses at $920 \mathrm{~nm}$ ( $90 \mathrm{fs}$, Tsunami and Model 3980 pulse picker, Spectra-Physics). The temporal resolution is $\sim 60$ ps. Data were analysed by using the nonlinear least-squares procedure in combination with an iterative convolution method.

Tautomer structure calculations. The theoretical approach used the SecondOrder Approximate Coupled-Cluster method (CC2) ${ }^{44}$ together with a resolutionof-the-identity technique to enhance performance. All atoms were employed using correlation-consistent basis sets of double- $\zeta$ quality with the diffuse and polarization functions (aug-cc-pVDZ) ${ }^{45}$. All calculations incorporated the solvation (COSMO model) ${ }^{46}$ for ground-state geometry optimization. All the theoretical calculations were performed with the TURBOMOLE programme

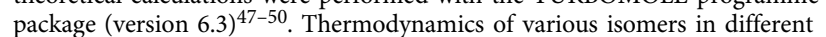
solvents were calculated using the DFT approach (B3LYP $6-311+\mathrm{g}(\mathrm{d}, \mathrm{p})$ ) incorporating a continuum solvation model (Gaussian 09) ${ }^{51}$. 


\section{References}

1. Ball, P. Water as an active constituent in cell biology. Chem. Rev. 108, 74-108 (2008).

2. Chaplin, M. Do we underestimate the importance of water in cell biology? Nat. Rev. Mol. Cell Biol. 7, 861-866 (2006).

3. Levy, Y. \& Onuchic, J. N. Water mediation in protein folding and molecular recognition. Annu. Rev. Biophys. Biomol. Struct. 35, 389-415 (2006).

4. Abel, R. et al. Contribution of explicit solvent effects to the binding affinity of small-molecule inhibitors in blood coagulation factor serine proteases. Chem. Med. Chem. 6, 1049-1066 (2011).

5. Robinson, D. D., Sherman, W. \& Farid, R. Understanding kinase selectivity through energetic analysis of binding site waters. Chem. Med. Chem. 5, 618-627 (2010).

6. Beuming, T. et al. Thermodynamic analysis of water molecules at the surface of proteins and applications to binding site prediction and characterization. Proteins 80, 871-883 (2012).

7. Wang, L., Berne, B. J. \& Friesner, R. A. Ligand binding to protein-binding pockets with wet and dry regions. Proc. Natl Acad. Sci. USA 108, 1326-1330 (2011)

8. Meister, K. et al. Long-range protein-water dynamics in hyperactive insect antifreeze proteins. Proc. Natl Acad. Sci. USA 110, 1617-1622 (2013).

9. Pal, S. K. \& Zewail, A. H. Dynamics of water in biological recognition. Chem. Rev. 104, 2099-2123 (2004).

10. Zhang, L. et al. Mapping hydration dynamics around a protein surface. Proc. Natl Acad. Sci. USA 104, 18461-18466 (2007)

11. Lakshmikanth, G. S. \& Krishnamoorthy, G. Solvent-exposed tryptophans probe the dynamics at protein surfaces. Biophys. J. 77, 1100-1106 (1999).

12. Ebbinghaus, S. et al. An extended dynamical hydration shell around proteins. Proc. Natl Acad. Sci. USA 104, 20749-20752 (2007).

13. Okada, T. et al. Functional role of internal water molecules in rhodopsin revealed by X-ray crystallography. Proc. Natl Acad. Sci. USA 99, 5982-5987 (2002).

14. Brand, L. \& Gohlke, J. R. Fluorescence probes for structure. Annu. Rev. Biochem. 41, 843-868 (1972).

15. Sackett, D. L. \& Wolff, J. Nile red as a polarity-sensitive fluorescent probe of hydrophobic protein surfaces. Anal. Biochem. 167, 228-234 (1987).

16. Ross, J. B., Szabo, A. G. \& Hogue, C. W. Enhancement of protein spectra with tryptophan analogs: fluorescence spectroscopy of protein-protein and proteinnucleic acid interactions. Methods Enzymol. 278, 151-190 (1997).

17. Cornish, V. W. et al. Site-specific incorporation of biophysical probes into proteins. Proc. Natl Acad. Sci. USA 91, 2910-2914 (1994).

18. Scott, D. J. et al. Quaternary re-arrangement analysed by spectral enhancement: the interaction of a sporulation repressor with its antagonist. J. Mol. Biol. 293, 997-1004 (1999).

19. Blouse, G. E. et al. A concerted structural transition in the plasminogen activator inhibitor-1 mechanism of inhibition. Biochemistry 41, 11997-12009 (2002).

20. De Filippis, V. et al. Incorporation of the fluorescent amino acid 7azatryptophan into the core domain 1-47 of hirudin as a probe of hirudin folding and thrombin recognition. Protein Sci. 13, 1489-1502 (2004).

21. Richmond, M. H. The effect of amino acid analogues on growth and protein synthesis in microorganisms. Bacteriol. Rev. 26, 398-420 (1962).

22. Mente, S. \& Maroncelli, M. Solvation and the excited-state tautomerization of 7-azaindole and 1-azacarbazole: Computer simulations in water and alcohol solvents. J. Phys. Chem. A 102, 3860-3876 (1998)

23. Smirnov, A. V. et al. Photophysics and biological applications of 7-azaindole and its analogs. J. Phys. Chem. B 101, 2758-2769 (1997).

24. Waluk, J. Hydrogen-bonding-induced phenomena in bifunctional heteroazaaromatics. Acc. Chem. Res. 36, 832-838 (2003).

25. Chapman, C. F. \& Maroncelli, M. Excited-state tautomerization of 7-azaindole in water. J. Phys. Chem. 96, 8430-8441 (1992).

26. Rich, R. L., Smirnov, A. V., Schwabacher, A. W. \& Petrich, J. W. Synthesis and photophysics of the optical probe $\mathrm{N}_{1}$-methyl-7-azatryptophan. J. Am. Chem. Soc. 117, 11850-11853 (1995).

27. Hoesl, M. G., Larregola, M., Cui, H. \& Budisa, N. Azatryptophans as tools to study polarity requirements for folding of green fluorescent protein. J. Pept. Sci. 16, 589-595 (2010)

28. Chen, Y., Gai, F. \& Petrich, J. W. Single-exponential fluorescence decay of the nonnatural amino acid 7-azatryptophan and the nonexponential fluorescence decay of tryptophan in water. J. Phys. Chem. 98, 2203-2209 (1994).

29. Chou, P. T., Yu, W. S., Wei, C. Y., Cheng, Y. M. \& Yang, C. Y. Water-catalysed excited-state double proton transfer in 3-cyano-7-azaindole: the resolution of the proton-transfer mechanism for 7-azaindoles in pure water. J. Am. Chem. Soc. 123, 3599-3600 (2001)

30. Chou, P. T. \& Chi, Y. Phosphorescent dyes for organic light-emitting diodes. Chem. Eur. J. 13, 380-395 (2007)

31. Denisov, I. G., Makris, T. M., Sligar, S. G. \& Schlichting, I. Structure and chemistry of cytochrome P450. Chem. Rev. 105, 2253-2277 (2005).

32. Zhao, B., Guengerich, F. P., Voehler, M. \& Waterman, M. R. Role of active site water molecules and substrate hydroxyl groups in oxygen activation by cytochrome P450 158A2: a new mechanism of proton transfer. J. Biol. Chem. 280, 42188-42197 (2005)

33. Yano, J. K. et al. The structure of human microsomal cytochrome P450 3A4 determined by X-ray crystallography to 2.05-A resolution. J. Biol. Chem. 279, 38091-38094 (2004).

34. Samuelsson, B. et al. Prostaglandins and thromboxanes. Annu. Rev. Biochem. 47, 997-1029 (1978)

35. Cheng, Y. et al. Role of prostacyclin in the cardiovascular response to thromboxane A2. Science 296, 539-541 (2002).

36. Williams, P. A. et al. Crystal structures of human cytochrome P450 3A4 bound to metyrapone and progesterone. Science 305, 683-686 (2004).

37. Attwell, D. et al. Glial and neuronal control of brain blood flow. Nature 468, 232-243 (2010)

38. Chao, W. C. et al. Probing ligand binding to thromboxane synthase. Biochemistry 52, 1113-1121 (2013).

39. Chao, W. C. et al. Probing the interaction between prostacyclin synthase and prostaglandin $\mathrm{H} 2$ analogues or inhibitors via a combination of resonance Raman spectroscopy and molecular dynamics simulation approaches. J. Am. Chem. Soc. 133, 18870-18879 (2011).

40. Chou, P. T. et al. Monohydrate catalysis of excited-state double-proton transfer in 7-azaindole. J. Phys. Chem. 96, 5203-5205 (1992).

41. Li, Y. C. et al. Structures of prostacyclin synthase and its complexes with substrate analog and inhibitor reveal a ligand-specific heme conformation change. J. Biol. Chem. 283, 2917-2926 (2008)

42. Chou, P. T. et al. Excited-state intramolecular proton transfer in 10hydroxybenzo(h)quinoline. J. Phys. Chem. A 105, 1731-1740 (2001).

43. Chou, P. T. et al. Femtosecond dynamics on excited-state proton/ charge-transfer reaction in $4^{\prime}$-N,N-diethylamino-3-hydroxyflavone. The role of dipolar vectors in constructing a rational mechanism. J. Phys. Chem. A 109, 3777-3787 (2005).

44. Christiansen, O., Koch, H. \& Jørgensen, P. The second-order approximate coupled cluster singles and doubles model CC2. Chem. Phys. Lett. 243, 409-418 (1995).

45. Dunning, J. T. H. Gaussian basis sets for use in correlated molecular calculations. I. The atoms boron through neon and hydrogen. J. Chem. Phys. 90, 1007-1023 (1989).

46. Eckert, F. \& Klamt, A. Fast solvent screening via quantum chemistry: COSMORS approach. AIChE J. 48, 369-385 (2002).

47. Ahlrichs, R., Bär, M., Häser, M., Horn, H. \& Kölmel, C. Electronic structure calculations on workstation computers: The program system turbomole. Chem Phys. Lett. 162, 165-169 (1989).

48. Hattig, C. \& Weigend, F. CC2 excitation energy calculations on large molecules using the resolution of the identity approximation. J. Chem. Phys. 113, 5154-5161 (2000).

49. Hattig, C. Geometry optimizations with the coupled-cluster model CC2 using the resolution-of-the-identity approximation. J. Chem. Phys. 118, 7751-7761 (2003).

50. Kohn, A. \& Hattig, C. Analytic gradients for excited states in the coupledcluster model CC2 employing the resolution-of-the-identity approximation. J. Chem. Phys. 119, 5021-5036 (2003).

51. Frisch, M. J. et al. Gaussian 09. revision A.02 (Gaussian Inc., 2009).

\section{Acknowledgements}

This work was supported by Grants NSC 101-2811-M-002-134 and 101-2113-M-030009-MY3 from the National Science Council of the Republic of China, a Cutting-Edge research grant from the National Taiwan University and a Medical Research Grant from the Medical School, Fu-Jen Catholic University. We thank Dr Ah-Lim Tsai and Lee-Ho Wang for their valuable comments. We also thank the National Center for High-Performance Computing for computational resources.

\section{Author contributions}

J.-Y.S. and S.C.-W.C. performed the chemical syntheses. C.L. and K.-C.T. measured and analysed the data. H.-A.P. performed the theoretical calculations. W.-C.C., L.-J.L., J.-S.W and J.-F.L. performed TXAS mutants, experiments and analysis. C.-L.C. and Y.-K.L. performed the MD simulation. H.-C.Y. and P.-T.C. co-wrote the paper. All the authors discussed the results and commented on the manuscript.

\section{Additional information}

Supplementary Information accompanies this paper at http://www.nature.com/ naturecommunications

Competing financial interests: The authors declare no competing financial interests.

Reprints and permission information is available online at http://npg.nature.com/ reprintsandpermissions/

How to cite this article: Shen, J.-Y. et al. Probing water micro-solvation in proteins by water catalysed proton-transfer tautomerism. Nat. Commun. 4:2611 doi: 10.1038/ ncomms3611 (2013). 